\title{
The effect of site (deltoid or gluteus muscle) of intramuscular administration of anaesthetic drugs on the course of immobilisation in macaque monkeys (Macaca mulatta)
}

\author{
Ladislav Hess ${ }^{1}$, Jiří Málek ${ }^{2}$, Alice Kurzová ${ }^{2}$, Martin Votava ${ }^{3}$ \\ ${ }^{1}$ Institute for Experimental and Clinical Medicine, Prague, Czech Republic \\ ${ }^{2}$ Department of Anaesthesiology and Resuscitation, ${ }^{3}$ Department of Pharmacology, Third Faculty of Medicine, \\ Charles University Prague, Czech Republic
}

Received March 30, 2010

Accepted March 7, 2012

\begin{abstract}
The aim of this work was to study the effect of site of intramuscular administration of anaesthetic drugs on the course of immobilisation in macaque monkeys (Macaca mulatta). Twenty macaque monkeys were given medetomidine $\left(25 \mu \mathrm{g} \cdot \mathrm{kg}^{-1}\right)$ and ketamine $\left(3 \mathrm{mg} \cdot \mathrm{kg}^{-1}\right)$ intramuscularly to the deltoid ( $\mathrm{n}=10$ animals) or gluteus $(\mathrm{n}=10$ animals) muscles. Behavioural changes, loss of aggressiveness, immobilisation time and cardiorespiratory changes were recorded. The effect of drugs was reversed after $20 \mathrm{~min}$ by i.m. administration of atipamezole at the dose of $250 \mu \mathrm{g}^{\cdot \mathrm{kg}^{-1}}$. Highly significant differences $(P<0.001)$ were found between groups with gluteal or deltoid administration of drugs on the onset of immobilisation effect (71.3 s and $108.3 \mathrm{~s}$, respectively), and immobilisation time (152.7 s and $254.4 \mathrm{~s}$, respectively). In the gluteus muscle group, the grasp reflex was still present at the beginning of immobilisation and slowly wore off in 15-45 s. The same was valid for muscle tone. There were no differences in cardiorespiratory parameters in any of the groups. Animals of both groups recovered in 3-6 min after atipamezole administration. Administration of drugs to the deltoid muscle resulted in a more rapid onset and increased effect of immobilisation than administration to the gluteus muscle. Both in veterinary and human medicine, injection to the deltoid muscle may be more convenient in all cases, when rapid and more prominent effect is desirable as in premedication before surgery or in emergency medicine. The study is the first to compare the effect of administering drugs to different muscles and the results may improve the practice of intramuscular injections in animals and in humans.
\end{abstract}

Medetomidine, ketamine, atipamezole, intramuscular injection

Intramuscular administration of various drugs used for anaesthesia and analgesia in humans is used in anaesthetic practice as well as in pre-hospital treatment mainly in burned patients or victims of a disaster. Many drugs including ketamine, benzodiazepines, opioids, anticholinergic drugs etc. are used by intramuscular route. In humans, a gluteal muscle is the most commonly used site of injection. Time to the onset of desired effect may be as long as $30 \mathrm{~min}$ and the effect may vary substantially (Tuttle 1977). Intramuscular anaesthesia and immobilisation are frequently used in veterinary medicine and the administration site is usually the deltoid muscle.

The aim of this study was to compare the differences in time of onset of sedation and immobilisation between administration of anaesthetic drugs (medetomidine and ketamine) to deltoid and gluteus muscles in rhesus monkeys.

\begin{abstract}
Methods
Animals

For the purpose of this study, twenty rhesus monkeys (Macaca mulatta), weighing 2.2-3.6 kg, 1-2 years of age, 10 males and 10 females were obtained from Biotest Konarovice, Czech Republic. The monkeys were housed in individual cages with an outdoor closure. Food and water were available ad libitum. Access to food was restricted $12 \mathrm{~h}$ prior to the start of the experiment procedure; access to water was not restricted. The study was approved by the Expert Committee for Protection of Experimental Animals of the IKEM Institute for Clinical and Experimental Medicine and was performed in accordance with the Animal Protection Act of the Czech Republic (No. 246/1992 Sb).
\end{abstract}

Address for correspondence:

Doc. MUDr. Ladislav Hess, DrSc.

IKEM Praha

Vídeňská 1958/9

14021 Praha 4, Czech Republic

Phone: +420236052518

E-mail: lahe@ikem.cz

http://actavet.vfu.cz/ 
Drugs

The following drugs were provided as standard commercial solutions: medetomidine (Domitor, Orion, Farmous Group- Finland) $1 \mathrm{mg} \cdot \mathrm{ml}^{-1}$, ketamine (Narketan, Vétoquinol, France) $100 \mathrm{mg} \cdot \mathrm{ml}^{-1}$ and atipamezole (Antisedan, Orion, Farmous Group- Finland) $5 \mathrm{mg} \cdot \mathrm{ml}^{-1}$.

Procedure

The weight of animals was measured before the experiment capturing the animal into a dip net. A $1 \mathrm{ml}$ syringe with $23 \mathrm{G}, 25 \mathrm{~mm}$ needle was used for injection. An intramuscular injection of a combination of medetomidine $\left(25 \mu \mathrm{g} \cdot \mathrm{kg}^{-1}\right)$ and ketamine $\left(3 \mathrm{mg} \cdot \mathrm{kg}^{-1}\right)$ was administered either into the musculus deltoideus of 10 animals (group $\mathrm{MD}$ ) or the gluteus muscle of the other 10 animals (group MG). The average weight of animals was $2726 \mathrm{~g}$ (SD $=514)$ in group $\mathrm{MD}$ and $2591 \mathrm{~g}(\mathrm{SD}=285)$ in group MG. There were 5 males and 5 females in each group. Because of the naturally aggressive behaviour of rhesus monkeys, the injection was administered after the animal was placed in the observational cage (size $1.5 \mathrm{~m} \times 1.5 \mathrm{~m} \times 2 \mathrm{~m}$ ) and while it was temporarily immobilized using the retractable rear wall of the cage. After administration of the drug, the animals were observed for behavioural changes, i.e. sedation, ataxia, tactile reaction, loss of aggressiveness. Following parameters were measured: lag time (an interval to the first signs of sedation and ataxia), immobilisation time (interval to lying down) and loss of grasp reflex (interval to loss of clench of a finger of an examiner after touching the palm of an animal). As soon as we were able to remove the monkey from the cage (after loss of aggressiveness), we began measuring basic cardiorespiratory parameters (pulse rate and oxygen saturation of haemoglobin - $\mathrm{SpO}_{2}$ ) by a pulse oximeter (Nonin $80500 \mathrm{~V}$ ) that was placed on a finger of the thoracic limb. These measurements were taken after $3 \mathrm{~min}$ and $5 \mathrm{~min}$ and then every $5 \mathrm{~min}$ for $20 \mathrm{~min}$. After this period, the alpha2-adrenoreceptor antagonist, atipamezole, was administered at a dose of $250 \mu \mathrm{g} \cdot \mathrm{kg}^{-1}$ to the deltoid muscle and again behavioural changes were observed.

Statistical analysis

Cardiorespiratory parameters were evaluated using two-way repeated measures ANOVA with post hoc StudentNewman-Keuls $t$-test. All statistical tests used a two-tailed criterion, with a significance level of $P<0.05$. For the ANOVA tests, F ratios (variance of the group means/mean of the within-group variance) with the corresponding degrees of freedom were presented.

\section{Results}

The main results are presented in Table 1. In group MG, no data for cardiorespiratory parameters could be obtained in the $3^{\text {rd }}$ min after administration of the drug because of the preserved consciousness and aggressiveness of the animals. There were highly significant differences $(P<0.001)$ between groups MG and MD in the onset of effect and immobilisation time. In the MG group, the grasp reflex was still present at the beginning of immobilisation and slowly wore off in 15-45 s. The same was valid for the muscle tone.

Table 1. Comparison of lag time, immobilisation time, time to loss of grasp reflex and cardiorespiratory parameters after administering medetomidine $\left(25 \mu \mathrm{g} \cdot \mathrm{kg}^{-1}\right)$ and ketamine $\left(3 \mathrm{mg} \cdot \mathrm{kg}^{-1}\right)$ to macaque monkeys (Macaca mulatta)

\begin{tabular}{lcc}
\hline & Group MD (10 animals) & Group MG $(10$ animals $)$ \\
\hline Lag time (s) & $71.3 \pm 11.7$ & $108.3 \pm 51.5^{*}$ \\
Immobilisation time (s) & $152.2 \pm 54.5$ & $250.6 \pm 88.6^{*}$ \\
Time to loss of grasp reflex (s) & $166.7 \pm 59.8$ & $307.8 \pm 143.2$ \\
$\mathrm{SpO}_{2}$ in 3 min & $96.1 \pm 2.2$ & no values obtained \\
$\mathrm{SpO}_{2}$ in 5 min & $96.9 \pm 2.2$ & $98.2 \pm 2.7$ \\
$\mathrm{SpO}_{2}$ in 10 min & $94.5 \pm 3.1$ & $98.0 \pm 1.6$ \\
$\mathrm{SpO}_{2}$ in 15 min & $96.0 \pm 3.3$ & $98.0 \pm 1.3$ \\
$\mathrm{SpO}_{2}$ in 20 min & $97.4 \pm 2.5$ & $97.0 \pm 3.4$ \\
$\mathrm{Pulse}$ rate in 3 min & $126.6 \pm 16.2$ & no values obtained \\
$\mathrm{Pulse}_{\text {rate in } 5 \text { min }}$ & $128.8 \pm 15.5$ & $128.0 \pm 21.5$ \\
Pulse rate in 10 min & $120.2 \pm 15.7$ & $121.9 \pm 18.2$ \\
Pulse rate in 15 min & $112.0 \pm 15.0$ & $113.4 \pm 15.4$ \\
Pulse rate in 20 min & $104.9 \pm 17.6$ & $107.2 \pm 12.6$ \\
\hline
\end{tabular}

The values are presented as average \pm SD (standard deviation)

MD - Animals injected medetomidine $\left(25 \mu \mathrm{g} \cdot \mathrm{kg}^{-1}\right)$ and ketamine $\left(3 \mathrm{mg} \cdot \mathrm{kg}^{-1}\right)$ to the deltoid muscle, MG - Animals injected medetomidine $\left(25 \mu \mathrm{g} \cdot \mathrm{kg}^{-1}\right)$ and ketamine $\left(3 \mathrm{mg} \cdot \mathrm{kg}^{-1}\right)$ to the gluteal muscle, $* P$ value $<0.001$ 
The heart rate and $\mathrm{SpO}_{2}$ values during immobilisation and recovery did not differ between groups.

Animals of both groups recovered on average 3-6 min after atipamezole administration.

\section{Discussion}

Studies examining the differences between various sites of injections are rare and sometimes conflicting (Tuttle 1977; Grabinski et al. 1983; Clutton et al. 1998). Our results demonstrate that the site of intramuscular administration is important for the onset of the anaesthetic effect. These finding are supported by studies examining pharmacokinetics of some drugs administered to various sites. Peak plasma concentration of $0.34 \pm 0.1 \mu \mathrm{g} \cdot \mathrm{l}^{-1}$ of the drug was achieved after $1.6-1.7 \mathrm{~h}$ when $1.5 \mu \mathrm{g} \cdot \mathrm{kg}^{-1}$ dexmedetomidine was injected to the gluteus muscle (Scheinin et al. 1992). When $2.0 \mu \mathrm{g} \cdot \mathrm{kg}^{-1}$ dexmedetomidine was administered to the deltoid muscle, the peak plasma concentration of $0.81 \pm 0.27 \mathrm{ng} \cdot \mathrm{ml}^{-1}$ of the drug was achieved after 12 (2-60) min (Dyck et al. 1993).

Evans et al. (1975) measured the blood flow in various muscles by $\mathrm{Xe}^{133}$. Blood perfusion of the deltoid muscle $(11.6 \pm 0.5 \mathrm{ml} / 100 \mathrm{~g} / \mathrm{min})$ was significantly higher $(P<0.05)$ than blood perfusion of the gluteus muscle $(9.6 \pm 0.5 \mathrm{ml} / 100 \mathrm{~g} / \mathrm{min})$. Blood flow in the same muscle volume is approximately $20 \%$ higher in the deltoid muscle and it means higher systemic absorption and more rapid increase of plasmatic concentration of the drug. Virkkila et al. (1993) studied the pharmacokinetics of $12.5 \mu \mathrm{g} \cdot \mathrm{kg}^{-1}$ alfentanil administered as premedication either to the deltoid or gluteus maximus muscle $15 \mathrm{~min}$ before peribulbar block in ophthalmic surgery in humans. They found significantly increased plasma concentration after the deltoid administration and only patients with the deltoid administration had reduced pain (measured by visual analogue scale) caused by peribulbar administration of local anaesthetics. Grabinski et al. (1983) discovered that plasma concentration of methadone was 2.5 higher after the deltoid administration than after the gluteal administration. Kentala et al. (1998) studied the pharmacokinetics of a combination $6 \mu \mathrm{g} \cdot \mathrm{kg}^{-1}$ scopolamine with morphine $200 \mu \mathrm{g} \cdot \mathrm{kg}^{-1}$ administered either to the deltoid or the gluteal muscle. After injection to the deltoid muscle, the peak plasma concentration of scopolamine $2.2 \mathrm{ng} \cdot \mathrm{l}^{-1}$ was achieved after $17 \mathrm{~min}$ versus $1.6 \mu \mathrm{g} \cdot \mathrm{kg}^{-1}$ and 19 min when scopolamine was administered to the gluteus muscle. Even more prominent were differences in morphine. The appropriate plasmatic concentrations were (deltoid vs.

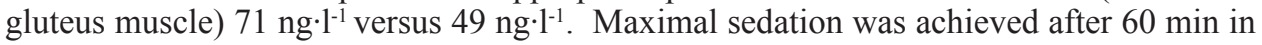
the deltoid group compared with 120-160 min in the gluteal group. The authors concluded that the pharmacokinetics and clinical effect of the scopolamine-morphine combination are more predictable and reliable after injection to the deltoid muscle. Similar situation was published in studies concerning muscle relaxant drugs.

Kuntze (1967) demonstrated that the effect of suxamethonium is more rapid after injection to the thoracic limb than to the pelvic limb. He demonstrated in felines, bears and ruminants that after administration of suxamethonium to the tail, the onset of muscle relaxation was significantly delayed and higher doses had to be used.

All studies mentioned above indicated that administration of drugs to the deltoid muscle resulted in a more rapid onset and increased effect of the drug. These conclusions are in agreement with our results. After injection of the combination medetomidine-ketamine to the deltoid muscle, a rapid onset of immobilisation, rapid cessation of the grasp reflex and complete muscle relaxation could be observed. On the other hand, after injection to the gluteus maximus muscle, the onset of immobilisation, loss of the grasp reflex and onset of muscle relaxation were delayed. We can speculate on the exact reason but based on the study of Evans et al. (1975) it is probably due to better blood supply to thoracic limbs.

We are aware that our results were obtained in fasting animals and different times could 
be obtained in non-fasting animals. We are not able to reproduce our study on non-fasting animals for safety reasons (risk of aspiration of the gastric content), but we can speculate that the differences between two different sites of intramuscular administration will be preserved, although absolute times could be probably prolonged.

The results of our study can be applied to humans, too. In the Czech Republic, intramuscular premedication is still commonly applied to the gluteal muscle. Absorption from this area is slow and unpredictable in some drugs such as diazepam (Tuttle 1977). In adult humans, the effect can be even more modified by a large variety in gluteal fat thickness causing improper deposition of the intended intramuscular injections in the gluteal muscle in some individuals. Burbridge (2007) demonstrated that in a significant number of patients, the medications may be injected subcutaneously and not into the gluteal musculature, possibly altering the pharmacokinetics of the administered medication. The fat tissue is less thick over the deltoid muscle.

We can conclude that the injection of drugs to the deltoid muscle may be more convenient in all cases when a rapid and more prominent effect is desirable as in premedication before surgery or in emergency medicine.

\section{Acknowledgments}

The study was supported by grant IGA MZCR NT11284-4/210 and VG20102015041.

\section{Reference}

Burbridge BE 2007: Computed tomographic measurement of gluteal subcutaneous fat thickness in reference to failure of gluteal intramuscular injections. Can Assoc Radiol J 58: 72-75

Clutton RE, Bracken J, Ritchie M 1998: Effect of muscle injection site and drug temperature on pre-anaesthetic sedation in pigs. Vet Rec 142: 718-721

Dyck JB, Maze M, Haack C, Vuorilehto L, Shafer SL 1993: The pharmacokinetics and hemodynamic effects of intravenous and intramuscular dexmedetomidine hydrochloride in adult human volunteers. Anesthesiology 78: $813-820$

Evans EF, Proctor JD, Fratkin MJ, Velandia J, Wasserman AJ 1975: Blood flow in muscle groups and drug absorption. Clin Pharmacol Ther 17: 44-47

Grabinski PY, Kaiko RF, Rogers AG, Houde R W 1983: Plasma levels and analgesia following deltoid and gluteal injections of methadone and morphine. J Clin Pharmacol 23: 48-55

Kentala E, Scheinin H, Kaila T, Seppala T, Kanto J 1998: Pharmacokinetics and clinical effects of intramuscular scopolamine plus morphine. A comparison of two injection sites. Acta Anaesthesiol Scand 42: 323-328

Kuntze A 1967: Beitrage zur Anaesthesie und medikamentellen Immobilisation der Zootiere (Ursiden, Feliden, Ruminantier) [Contribution to anaesthesia and drug-induced immobilization of animals in zoos (bears, cats and ruminants)]. Berlin u. Hamburg, Paul Parey, p. 153

Scheinin H, Karhuvaara S, Olkkola K T, Kallio A, Anttila M, Vuorilehto L, Scheinin M 1992: Pharmacodynamics and pharmacokinetics of intramuscular dexmedetomidine. Clin Pharmacol Ther 52: 537-546

Tuttle CB 1977: Intramuscular injections and bioavailability. Am J Hosp Pharm 34: 965-968

Virkkila M, Ali-Melkkila T, Soini H, Kanto J 1993: Pharmacokinetics and effects of i.m. alfentanil as premedication for day-case ophthalmic surgery in elderly patients. Br J Anaesth 71: 507-511 